\title{
Muscle lipogenesis balances insulin sensitivity and strength through calcium signaling
}

\author{
Katsuhiko Funai, ${ }^{1}$ Haowei Song, ${ }^{1}$ Li Yin, ${ }^{1}$ Irfan J. Lodhi, ${ }^{1}$ Xiaochao Wei, ${ }^{1}$ Jun Yoshino, ${ }^{2}$ \\ Trey Coleman, ${ }^{1}$ and Clay F. Semenkovich ${ }^{1,3}$ \\ ${ }^{1}$ Division of Endocrinology, Metabolism and Lipid Research, ${ }^{2}$ Division of Geriatrics and Nutritional Science, Department of Medicine, and \\ ${ }^{3}$ Department of Cell Biology and Physiology, Washington University School of Medicine, St. Louis, Missouri, USA.
}

\begin{abstract}
Exogenous dietary fat can induce obesity and promote diabetes, but endogenous fat production is not thought to affect skeletal muscle insulin resistance, an antecedent of metabolic disease. Unexpectedly, the lipogenic enzyme fatty acid synthase (FAS) was increased in the skeletal muscle of mice with diet-induced obesity and insulin resistance. Skeletal muscle-specific inactivation of FAS protected mice from insulin resistance without altering adiposity, specific inflammatory mediators of insulin signaling, or skeletal muscle levels of diacylglycerol or ceramide. Increased insulin sensitivity despite high-fat feeding was driven by activation of AMPK without affecting AMP content or the AMP/ATP ratio in resting skeletal muscle. AMPK was induced by elevated cytosolic calcium caused by impaired sarco/endoplasmic reticulum calcium ATPase (SERCA) activity due to altered phospholipid composition of the sarcoplasmic reticulum (SR), but came at the expense of decreased muscle strength. Thus, inhibition of skeletal muscle FAS prevents obesity-associated diabetes in mice, but also causes muscle weakness, which suggests that mammals have retained the capacity for lipogenesis in muscle to preserve physical performance in the setting of disrupted metabolic homeostasis.
\end{abstract}

\section{Introduction}

By 2050, 1 in 3 Americans may have obesity-related type 2 diabetes, an often lethal condition (1) characterized by insulin resistance $(2,3)$. Skeletal muscle insulin resistance accounts for approximately $90 \%$ of impaired glucose disposal in human type 2 diabetes (4), and abnormal lipid metabolism is implicated in this process (5). Manipulating genes affecting different steps in lipid handling produces varying effects on glucose metabolism that have been interpreted to reflect increased insulin sensitivity with decreased intracellular fatty acid content (6-11). Despite this apparently inverse relationship between lipid content and insulin sensitivity, there is no consensus regarding how fatty acid flux in muscle affects insulin sensitivity $(12,13)$. Unexplored is the possibility that endogenous lipid synthesis in skeletal muscle affects diabetes risk.

Fatty acid synthase (FAS) (14) uses products of the citric acid cycle to synthesize the saturated fatty acid palmitate, contributing to de novo lipogenesis. Skeletal muscle de novo lipogenesis is not thought to be a major contributor to total muscle fatty acid flux (15). However, several lines of evidence suggest that de novo lipogenesis may serve a signaling function independent of providing lipid storage (16). As one example, FAS generates an endogenous ligand for the nuclear receptor PPAR $\alpha$ in liver (17). PPAR $\alpha$ is also found in muscle, where its overexpression has been implicated in the pathogenesis of insulin resistance (18). These observations raise the possibility that fatty acid flux generated by skeletal muscle FAS could promote insulin resistance through activation of PPAR $\alpha$.

To test the hypothesis that FAS affects skeletal muscle insulin sensitivity, we selectively inactivated FAS in this tissue. Our findings suggest that mice deficient in de novo lipogenesis were protected from skeletal muscle insulin resistance induced by high-fat

Conflict of interest: The authors have declared that no conflict of interest exists. Citation for this article: J Clin Invest. 2013;123(3):1229-1240. doi:10.1172/JCI65726. diet (HFD) feeding. However, this protection did not appear to be mediated by PPAR $\alpha$. Instead, FAS deficiency in muscle altered the phospholipid composition and transport functions of the sarcoplasmic reticulum (SR; a relative of the endoplasmic reticulum adapted to sequester calcium), leading to elevated cytosolic calcium concentrations. Elevated intracellular calcium increased glucose transport through AMPK, but this metabolic benefit came at the cost of decreasing physical performance. Improved insulin sensitivity appeared to be physiologically connected to muscle fatigue through increased cytosolic calcium, which activated AMPK but likely prevents appropriate relaxation of muscle fibers, thus limiting optimal subsequent contraction.

\section{Results}

Skeletal muscle FAS is associated with insulin resistance. 4 weeks of feeding HFD to control mice predictably increased levels of glucose, insulin, and other metabolites affected by insulin resistance (see below). This intervention is known to decrease FAS expression at major sites of lipogenesis, such as liver and white adipose tissue $(19,20)$. Surprisingly, HFD feeding did not suppress FAS in muscle: $\mathrm{mRNA}$, protein, and enzyme activity of FAS were increased in skeletal muscle after 4 weeks of HFD feeding (Figure 1A and Supplemental Figure 1A; supplemental material available online with this article; doi:10.1172/JCI65726DS1). FAS protein abundance was greater in slow-twitch muscles that are susceptible to diet-induced insulin resistance (21), such as soleus (Figure 1B), which suggests that muscle FAS may promote insulin resistance. To address this possibility, we crossed mice bearing loxP sites in Fasn (22) with transgenic mice expressing Cre recombinase driven by the human $\alpha$-skeletal actin promoter (23). This strategy yielded $\underline{\text { FAS }}$ knockout in skeletal muscle (FASKOS) mice.

FASKOS mice are protected from diet-induced skeletal muscle insulin resistance. FASKOS mice had deficient FAS expression in skeletal 
A
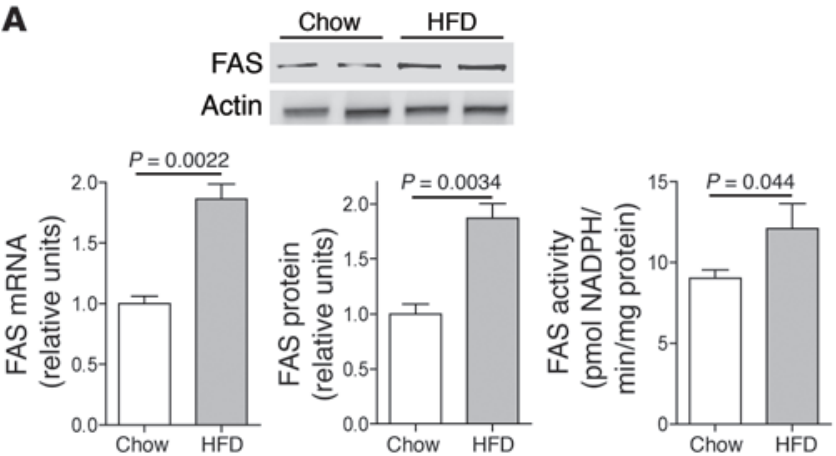

B

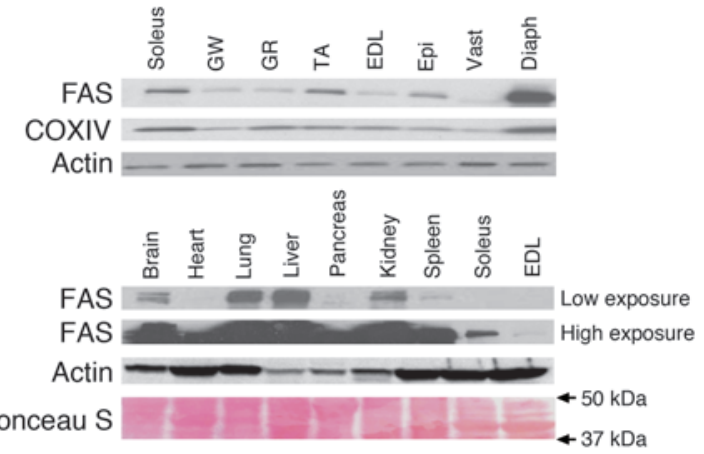

C
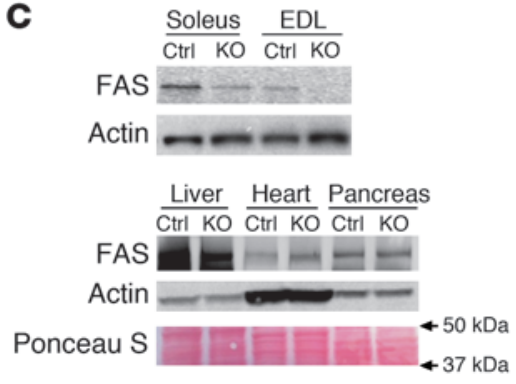

CtrI KO $\frac{\text { Ctrl KO }}{\text { Ctrl KO }}$

FAS

Ponceau S
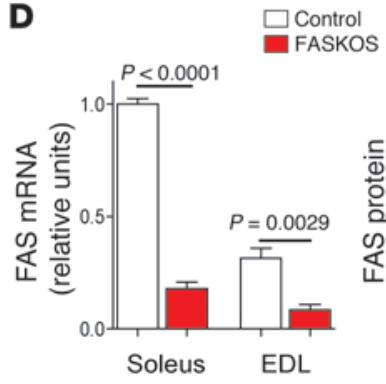

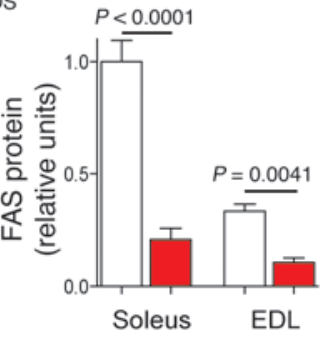

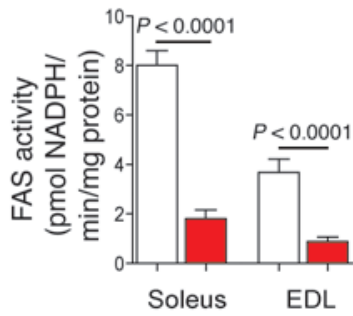

Figure 1

Induction of skeletal muscle FAS by HFD feeding and FASKOS mouse generation. (A) FAS mRNA, protein, and enzyme activity in soleus muscles from mice fed chow or HFD ( $n=7$ per group). (B) Western blot analyses of FAS protein expression in various muscles (top) and tissues (bottom). GW, gastrocnemius (white); GR, gastrocnemius (red); TA, tibialis anterior; Epi, epitrochlearis; Vast, vastus lateralis; Diaph, diaphragm; COXIV, mitochondrial cytochrome c oxidase subunit IV. (C) FAS Western blots from muscles (top) and other tissues (bottom) in control and FASKOS mice. (D) FAS mRNA ( $n=6$ per genotype), protein ( $n=7$ per genotype), and enzyme activity ( $n=10$ per genotype) in control and FASKOS mice. Data are mean \pm SEM.

muscle, but not in liver, heart, or pancreas (Figure 1, C and D, and Supplemental Figure 1B). There was no genotype-specific effect on body weight or composition, as determined by MRI, with chow or HFD feeding (Figure 2A). Tissue weights of skeletal muscles, liver, and adipose depots were unaffected in FASKOS mice (Figure 2, B and C). Serum levels of glucose, free fatty acids, triglycerides, and cholesterol as well as of insulin and leptin were higher in HFDversus chow-fed animals, but these effects were the same in control and FASKOS mice (Figure 2, D and E). The total skeletal muscle content of triglycerides, free fatty acids, malonyl-CoA, diacylglycerol (DAG), ceramide, and other sphingolipid species did not differ between HFD-fed control and FASKOS mice (Figure 3, A-E, and data not shown). These negative results are consistent with previous reports of low levels of lipogenic genes, including FAS, in skeletal muscle compared with expression of malonyl-CoA decarboxylase (15), which suggests that FAS does not have major effects on the total mass of lipids and lipid precursors in muscle.

Muscle FAS deletion did not alter metabolic rate, as measured by indirect calorimetry (Figure 4A). Respiratory quotient (RQ; reflecting choice of carbohydrate or lipid for energy production, with a lower value indicating more lipid use) was decreased in HFD-fed control mice that were awake and eating (during the dark phase of a daily cycle; Figure 4B), suggestive of less postprandial carbohydrate metabolism consistent with HFD-induced insulin resistance. However, FASKOS mice were partially protected from this HFDinduced attenuation of $R Q$ in the dark phase (Figure 4B), indicative of increased use of carbohydrates as fuel. To determine wheth- er this preference for carbohydrate was due to increased insulin sensitivity, FASKOS mice were further metabolically phenotyped.

Glucose and insulin tolerance tests showed that with chow feeding, FASKOS mice were indistinguishable from control mice (Figure 4, C and D). However, FASKOS mice were partially protected from HFD-induced glucose intolerance and insulin resistance (Figure 4, E and F). In hyperinsulinemic euglycemic clamp studies, the insulin-stimulated glucose disposal rate was 4 -fold greater in FASKOS than in control mice, whereas there was no difference in the ability of insulin to suppress endogenous glucose production (mostly reflecting hepatic effects) or release of fatty acids from fat (Figure 5, A-E). The findings that increased glucose disposal occurred in the absence of differences in adiposity, potential circulating contributors to insulin resistance, or metabolic rate (Figures 2 and 4) suggest that muscle FAS deficiency increased insulin sensitivity through effects intrinsic to muscle.

Muscle FAS deletion results in intrinsic AMPK activation. Insulin-stimulated glucose uptake in skeletal muscle is mediated by translocation of GLUT4 to the cell surface (24). In muscles isolated after the clamp, GLUT4 abundance was not different between control and FASKOS mice (Figure 5F). There was also no effect of FAS deletion on phosphorylation of Akt ( $\mathrm{pAkt}^{\mathrm{Thr} 308}$ and $\left.\mathrm{pAkt}^{\mathrm{Ser} 473}\right)$ or of its substrate, glycogen synthase kinase-3 (GSK3), in insulin-stimulated muscles, which suggests that these mediators of insulin receptor signaling are not involved in the FASKOS phenotype. However, phosphorylation of Akt substrate of $160 \mathrm{kDa}$ (AS160), an Akt substrate Rab GTPase activating protein known to regulate GLUT4 
A
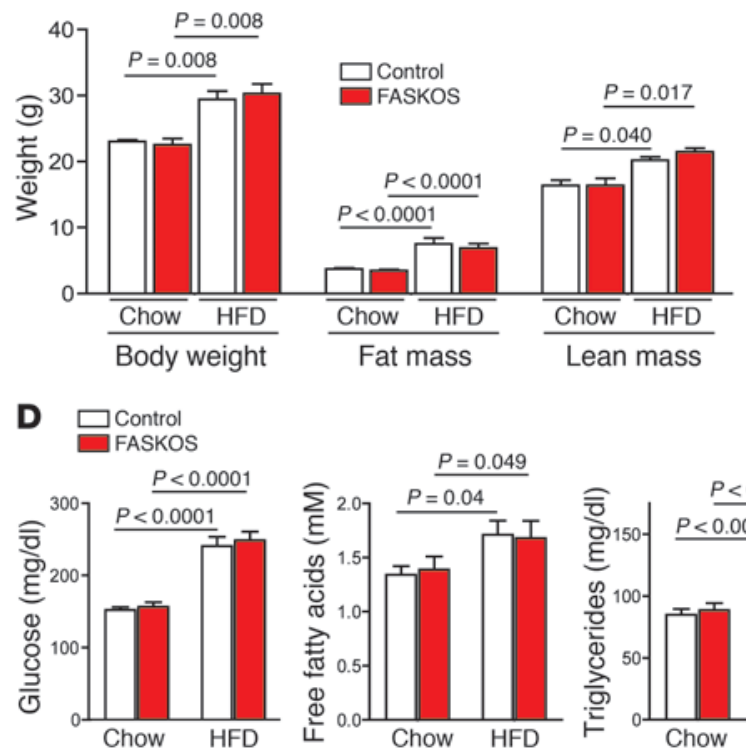
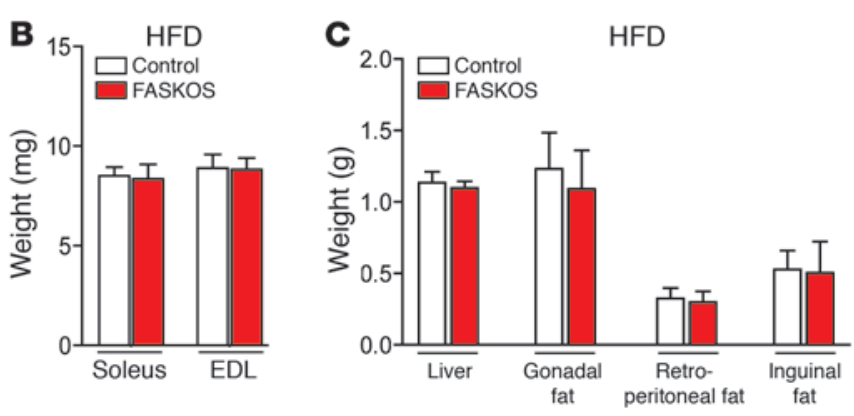

E $\square$ Control
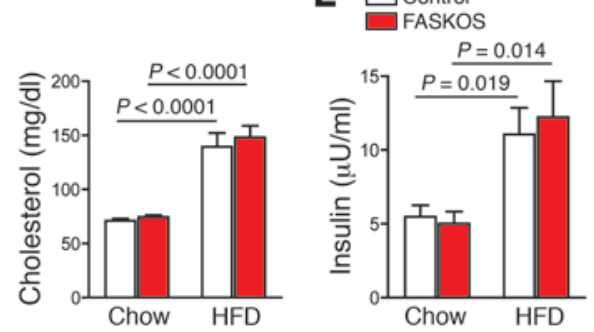

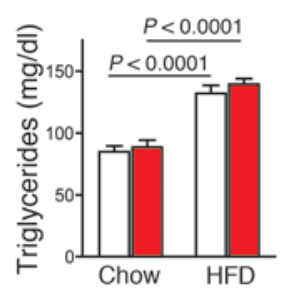

Figure 2

Phenotyping of FASKOS mice. (A) Body weight and composition of control and FASKOS mice ( $n=8$ per genotype). (B and C) Soleus and EDL weights (B) and liver and adipose tissue weights (C) in HFD-fed control and FASKOS mice ( $n=7$ per genotype). (D) Serum chemistries. (E) Serum hormones. Data are mean \pm SEM.

translocation $(25,26)$, was increased in the muscles from FASKOS compared with control mice (Figure 5F). AS160 phosphorylation is permissive for glucose transport. In addition to Akt, AMPK can phosphorylate AS160 $(27,28)$. Phosphorylation of AMPK and its substrate, acetyl-CoA carboxylase (ACC), were found to be elevated in FASKOS versus control mice (Figure 5F). Because AMPK enhances muscle insulin sensitivity, these results suggest that the insulin sensitivity phenotype in HFD FASKOS mice may be due to muscle-intrinsic AMPK activation.

Soleus muscles were isolated from control and FASKOS mice fed chow or HFD, then incubated with 2-deoxyglucose. As with intact animals, there was no effect of FAS inactivation in the chow condition, but soleus and extensor digitorum longus (EDL) muscles isolated from FASKOS mice were partially protected from the HFD-induced reduction of insulin-stimulated glucose uptake (Figure 6A and Supplemental Figure 2). Western blotting of these isolated muscles confirmed the findings of others that HFD decreased AMPK activation in control muscles $(29,30)$ and showed that FASKOS muscles were protected from this suppression of AMPK activation (reflected as phosphorylation of AMPK itself as well as of ACC; Figure 6, $\mathrm{B}$ and $\mathrm{C})$. Mirroring the findings in intact mice, Akt activation was unaffected, whereas AS160

\section{Figure 3}

Skeletal muscle metabolites in HFD-fed control and FASKOS mice. (A) Triglycerides, (B) free fatty acids, (C) malonyl-CoA, (D) DAG species, and (E) ceramide species ( $n=4$ per group). Data are mean \pm SEM. phosphorylation was increased, in muscle of HFD-fed FASKOS mice (Figure 6, D and E). These observations suggest that FASKOS muscle is protected from HFD-induced suppression of AMPK activity and, since HFD feeding increased muscle FAS activity (Figure 1A), that skeletal muscle FAS inhibits AMPK activation.

Muscle-intrinsic AMPK activation is mediated by increased cytosolic calcium. To determine whether regulation of AMPK by FAS can be modeled in a cell line, C2C12 myocytes were treated with a lentivirus expressing an FAS shRNA. C2C12 cells are a transformed cell line with metabolic needs differing from those of intact muscle, but there is precedent for the use of these cells to gain insight into
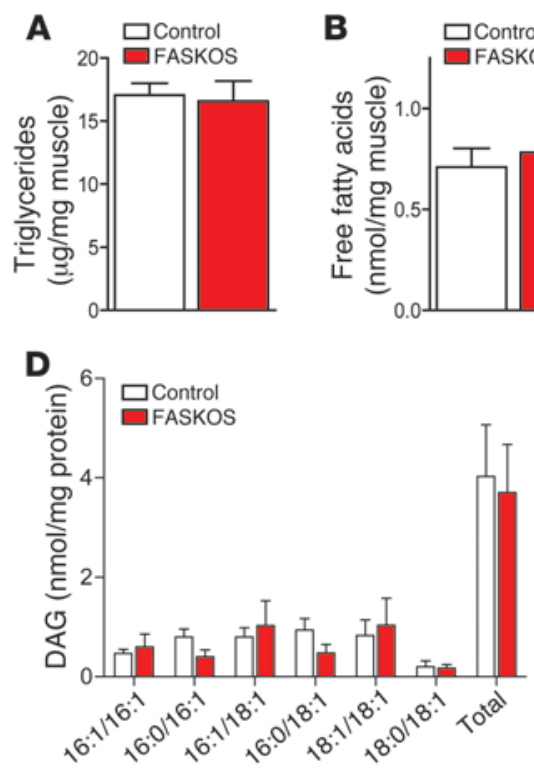
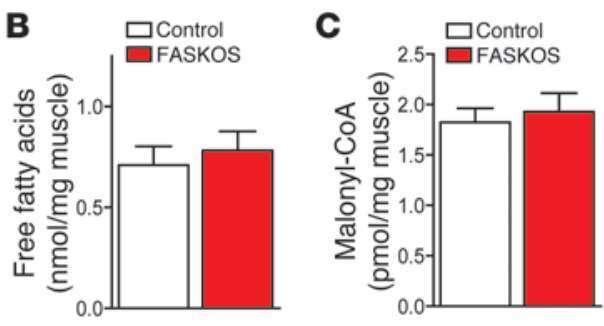

E

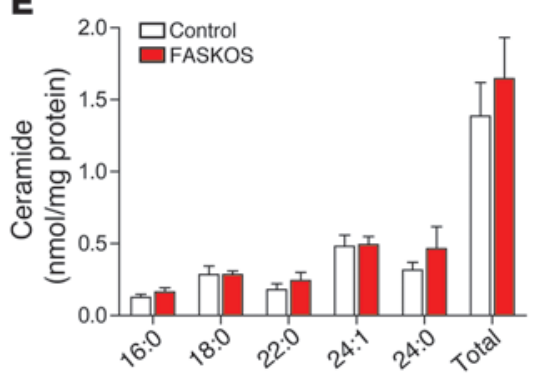



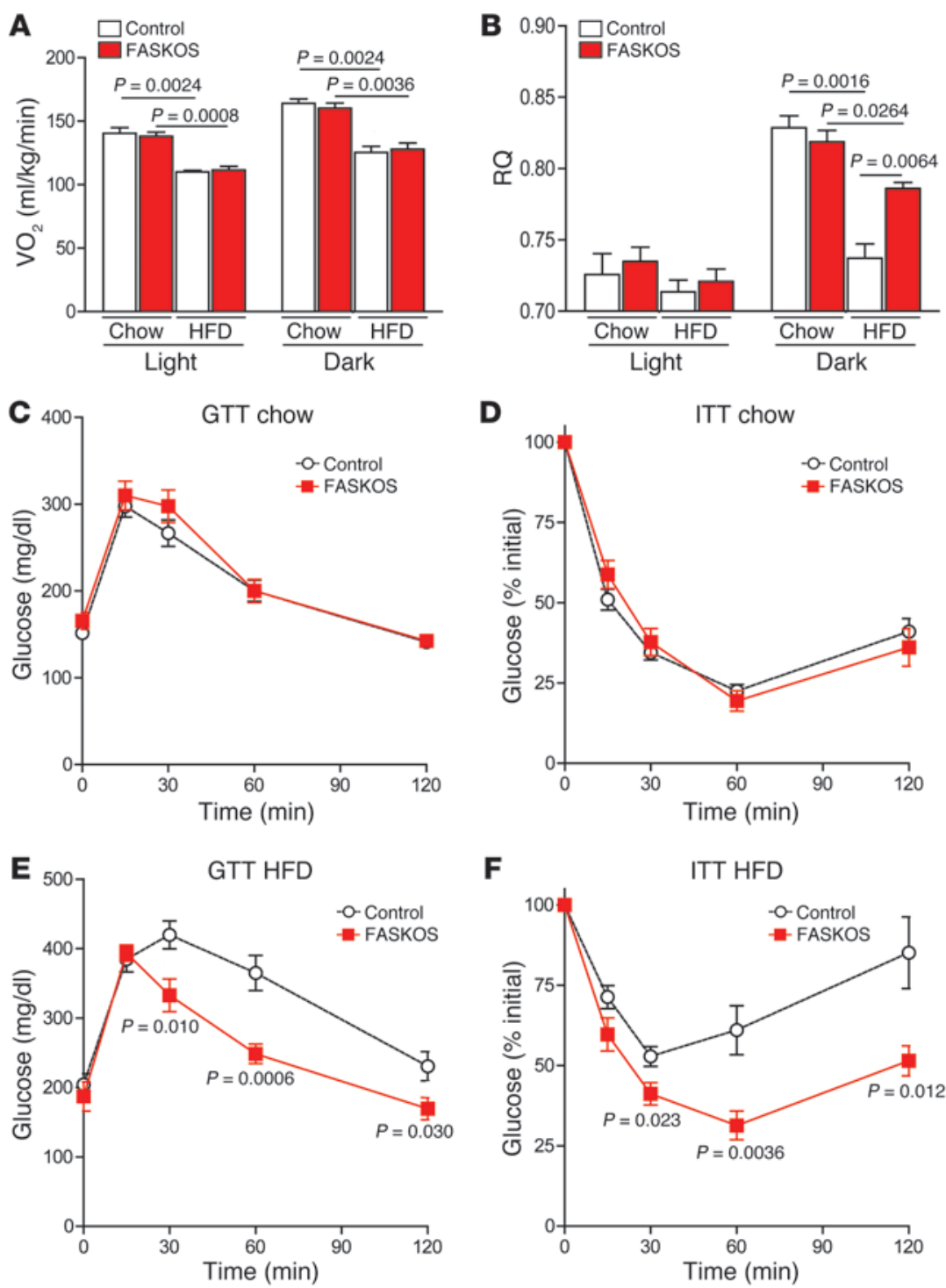

\section{Figure 4}

FASKOS mice are protected from diet-induced whole-body glucose intolerance and insulin resistance. (A) $\mathrm{VO}_{2}$ in control and FASKOS mice. (B) RQ. (C-F) Glucose tolerance tests (GTT; $\mathbf{C}$ and E) and insulin tolerance tests (ITT; $\mathbf{D}$ and $\mathbf{F}$ ) in mice fed chow (C and D) or HFD (E and F). $n=5$ (A and B), 10 (C, D, and F), or 12 (E) per genotype. Data are mean \pm SEM.

signaling (data not shown), and fatty acid oxidation rates were not different from controls in muscles or $\mathrm{C} 2 \mathrm{C} 12$ cells with FAS deletion (Supplemental Figure 3, C and D). Inflammation can play a role in insulin sensitivity, but there was no effect of FAS deletion on JNK or IKB $\alpha$ activity in skeletal muscle (Supplemental Figure 4). There was also no detectable interaction between FAS and AMPK in co-IP experiments (data not shown). Therefore, the effect of muscle FAS deletion on AMPK activation does not appear to be mediated by PPAR $\alpha$, AMP levels, altered fatty acid oxidation, inflammation, or a direct effect of FAS on AMPK.

AMPK can be phosphorylated by liver kinase B1 (LKB1) or $\mathrm{Ca}^{2+} /$ calmodulin-dependent kinase kinase- $\beta$ (CaMKK $\beta)$. FASKD did not affect mRNA levels or protein abundance of LKB1, CaMKK $\alpha$, or CaMKK $\beta$ (Supplemental Figure 5). LKB1 appears to be constitutively active, but CaMKK $\beta$ is activated by increased cytosolic calcium (32). Since FAS inactivation in cardiac muscle increases calcium signaling (33), and calcium (34), calmodulin (35), and CaMKII (36) have been implicated in glucose uptake, we addressed a potential role for calcium. In C2C12 myocytes, cytosolic calcium content increased in response to FASKD (Figure 7, D and E). The increase in cytosolic calcium triggered the $\mathrm{Ca}^{2+} /$ calmodulin signaling cascade in C2C12

processes relevant to the role of muscle in physiology (31). FAS knockdown (FASKD) had no effect on activation of Akt or GSK3 compared with control cells treated with a scrambled virus, but increased phosphorylation of AMPK as well as of its targets, ACC and AS160 (Figure 7A), replicating the effects in FASKOS skeletal muscle. FAS generates an endogenous ligand for the nuclear receptor PPAR $\alpha$ in liver (17), and PPAR $\alpha$ deletion activates AMPK in skeletal muscle (18), which raises the possibility that FAS deletion affects AMPK through PPAR $\alpha$. However, FAS deletion did not affect PPAR $\alpha$ luciferase activity, and treatment with the PPAR $\alpha$ agonist WY14643 did not reverse FASKD-induced AMPK activation (Figure 7, B and C). AMPK can be allosterically activated by AMP, but AMP content and the AMP/ATP ratio were unaffected by FAS deletion (Supplemental Figure 3, A and B). Total skeletal muscle malonyl-CoA levels were not different between control and FASKOS mice (Figure 3C). It is conceivable that changes in malonyl-CoA limited to discrete subcellular compartments might activate AMPK by inhibiting carnitine palmitoyl transferase- 1 and fatty acid oxidation. However, incubation of C2C12 myocytes with the fatty acid oxidation inhibitor etomoxir did not alter AMPK myocytes (Figure 8, A and B). Activation of CaMKK $\beta$ (detected as CaMKI phosphorylation) was also found in clamped as well as isolated FASKOS muscles (Figure 8, C and D). To determine whether CaMKK $\beta$ was required for the effect of FAS deletion on AMPK activation, we inhibited CaMKK $\beta$ in the setting of FASKD in C2C12 myocytes. FASKD-induced AMPK activation was abrogated by CaMKK $\beta$ knockdown, which was confirmed by treatment with a chemical inhibitor of CaMKK, STO-609 (Figure 8, E and F). These data suggest that induction of AMPK activity with FAS deletion is related to increased calcium signaling.

Muscle FAS affects SERCA by altering SR phospholipid composition. Control of cytosolic calcium in skeletal muscle is mediated by transporters found at the plasma membrane and at the SR. Dogma holds that FAS is exclusively cytoplasmic, but subcellular fractionation studies of skeletal muscle unexpectedly showed that, in addition to the cytoplasm, SR was also highly enriched in FAS (Figure 9A). To address the possibility that FAS physically interacts with SR proteins to regulate calcium flux, the SR fraction from mouse hindlimb muscles was treated with an FAS antibody, and the immunoprecipitated proteins were identified by 

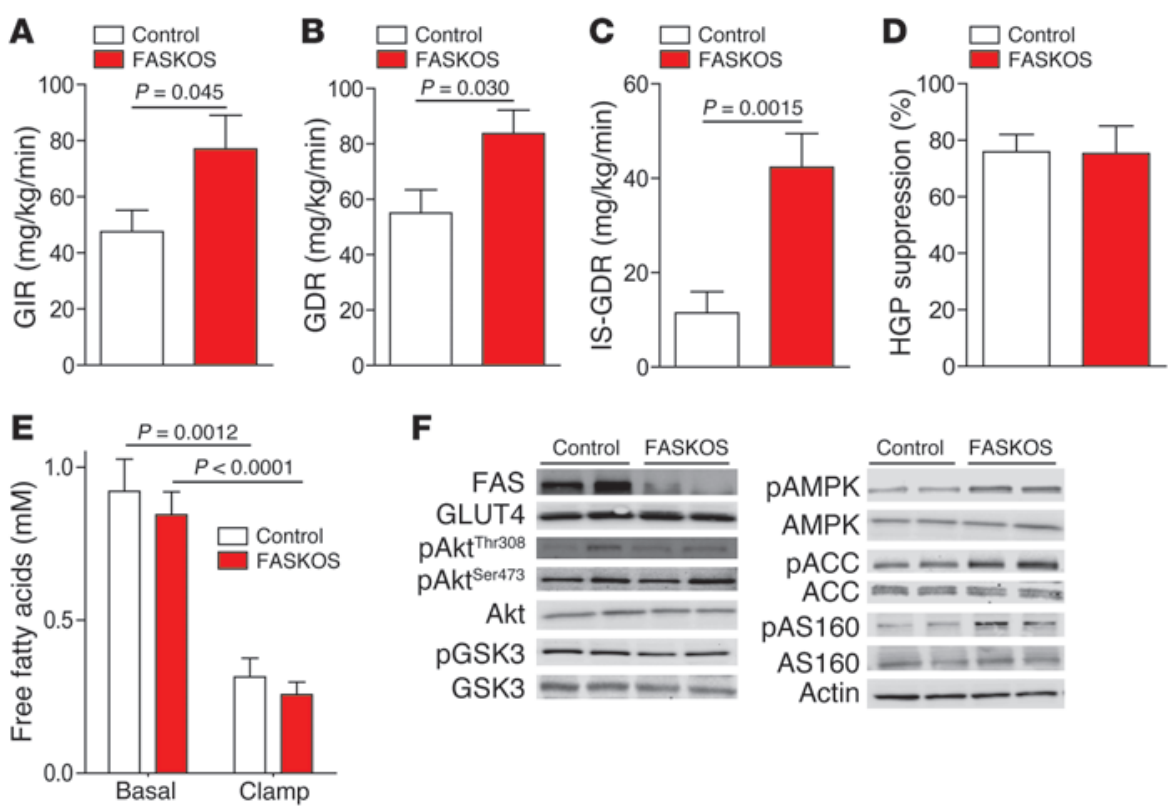

$\mathbf{F}$
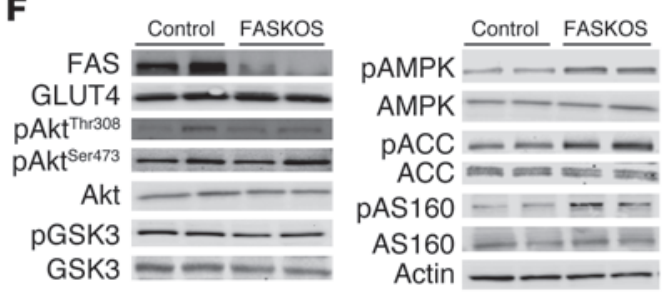

\section{Figure 5}

Hyperinsulinemic euglycemic clamp studies in HFD-fed control and FASKOS mice. (A) Glucose infusion rate (GIR), (B) glucose disposal rate (GDR; during clamp phase), (C) insulin-stimulated glucose disposal rate (IS-GDR; calculated difference between clamp and basal phases), and (D) suppression of hepatic glucose production (HGP) ( $n=10$ [control]; 8 [FASKOS]). (E) Circulating free fatty acids during basal and clamp phase ( $n=7$ per genotype). $(\mathbf{F})$ Western blot analyses of soleus from clamp studies. Data are mean \pm SEM. mass spectrometry (Supplemental Table 1). It is likely that several of these proteins do not reside in the SR, given the sensitivity of mass spectrometry and possible contamination of the SR fraction with proteins from other compartments. However, 3 isoforms of sarco/endoplasmic reticulum calcium ATPase (SERCA), the ATPase that transports cytosolic calcium to the SR lumen, were detected. Results of co-IP experiments using SERCA1 and SERCA2 antibodies were consistent with an association between these 2 proteins and FAS (Figure 9B). ACC did not appear to interact with the SERCAs (Figure 9B). Immunofluorescence colocalization studies in $\mathrm{C} 2 \mathrm{C} 12$ cells also suggested an interaction between FAS and SERCA1 (Figure 9C). FAS also colocalized with the endoplasmic reticulum/SR marker calnexin, but not with the Golgi marker GM130 (Figure 9C). FASKD in C2C12 myocytes decreased SERCA enzyme activity without affecting SERCA1 protein abundance (Figure 9D). Transfecting C2C12 myocytes with a vector expressing myc-tagged SERCA1 restored SERCA enzyme activity (Figure 9D). Expressing myc-tagged SERCA1 also eliminated the FASKD-induced increase in AMPK phosphorylation (Figure 9E), consistent with the concept that FAS inactivation impairs SERCA activity to activate AMPK. FASKD did not affect myc-tagged SERCA1 expression (Figure 9E). In addition, SERCA enzyme activity was decreased in soleus and EDL muscle of HFDfed, but not chow-fed, FASKOS mice without affecting SERCA1 protein abundance (Figure 9F and Supplemental Figure 6). These data suggest that FAS promotes SERCA activity in muscle and that a reduction in SERCA activity may mediate AMPK activation and increased insulin sensitivity in FAS-deficient muscles.

FAS is involved in palmitoylation of certain proteins to promote their membrane association $(37,38)$. However, neither SERCA1 nor SERCA2 was palmitoylated in sensitive assays involving replacement of biotin for palmitate at cysteine residues (data not shown).

To determine whether the lipid environment of the SR is altered by FAS deficiency, the SR fraction of hindlimb muscle was isolated and analyzed by mass spectrometry. The ratio of phosphatidylcholine (PC) to phosphatidylethanolamine (PE) was not affected by FAS deficiency in the SR with chow feeding, but increased in the SR of HFD-fed FASKOS muscle (Figure 10A). This change reflected the relative lack of a HFD-induced increase in PE content and a more robust HFD-induced increase in PC content in FASKOS mice (Figure 10, B and C). For PE, the SR changes were particularly pronounced for a specific species, 16:0/22:6 PE (Figure 10D). For PC, several species were affected, most prominently 16:1/18:1 PC (Figure 10E). Under chow- and HFD-fed conditions, skeletal muscle FAS deletion did not affect PC or PE content in the nucleus or mitochondria (Supplemental Figures 7 and 8). However, FASKD in C2C12 cells was associated with an increased PC/ $\mathrm{PE}$ ratio and decreased PE content in the SR (Supplemental Figure 9). PE is known to increase the affinity of calcium for SERCA (39), and an increased PC/PE ratio is associated with decreased SERCA activity in mouse liver (40), which suggests that altered lipid composition of the SR mediates decreased SERCA activity in FASKOS muscle. Note that the SERCA activity pattern for control and FASKD C2C12 cells was inversely related to the PC/PE ratio in SR of C2C12 cells (Figure 9D and Supplemental Figure 9); the SERCA activity pattern for muscle of HFD-fed control and FASKOS mice was also inversely related to the SR PC/PE ratio for this muscle (Figure 9F and Figure 10A).

FASKOS mice are prone to diet-induced muscle weakness. SERCA is critical for muscle contraction, allowing fiber relaxation through the efficient uptake of cytosolic calcium. Force production is profoundly decreased in SERCA1-null mice (41). Conversely, SERCA1 overexpression improves muscle capacity in muscular dystrophy (42). As shown in Figure 11A, forelimb strength paralleled SERCA activity (Figure 9F) in FASKOS mice: strength was unaffected on a chow diet but decreased with HFD feeding. This muscle contractile abnormality was also demonstrated when HFD-fed FASKOS mice were subjected to high-intensity treadmill running. FASKOS mice performed less well than control mice in terms of both running time and distance (Figure 11, B and $\mathrm{C}$, and Supplemental Video 1). These observations suggest that while FAS deletion in skeletal muscle triggers calcium signaling benefiting glucose homeostasis, this effect compromises skeletal muscle contractile function. 
A

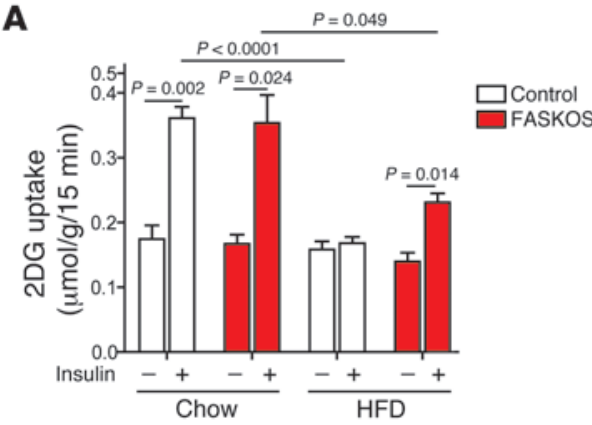

B
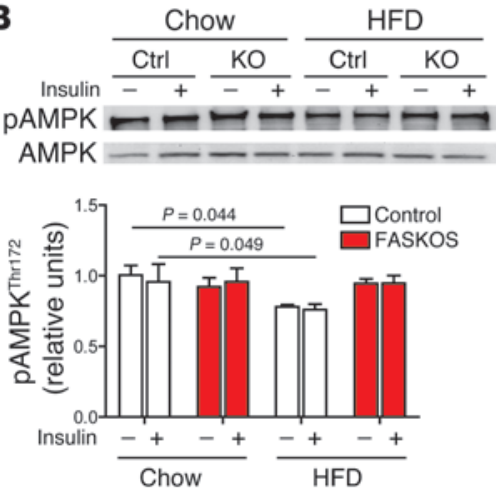

D

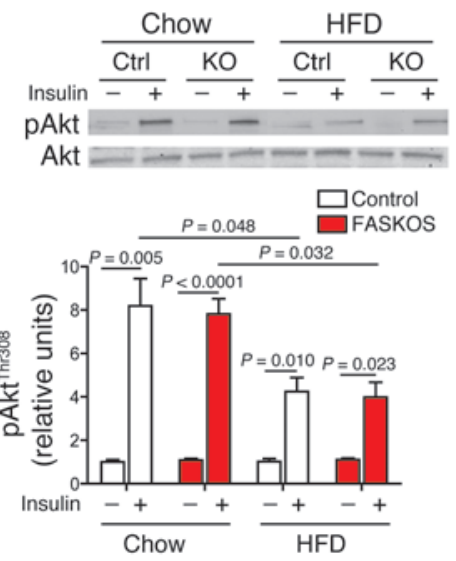

C
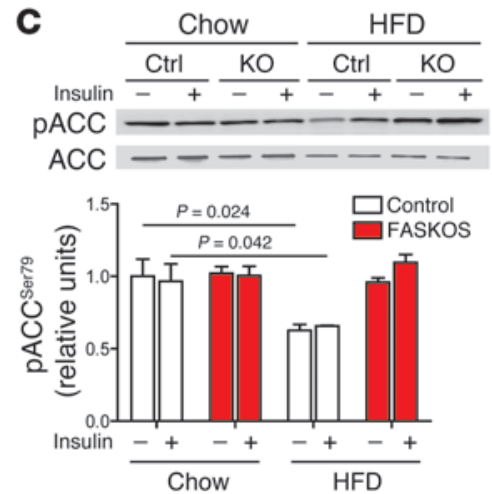

E
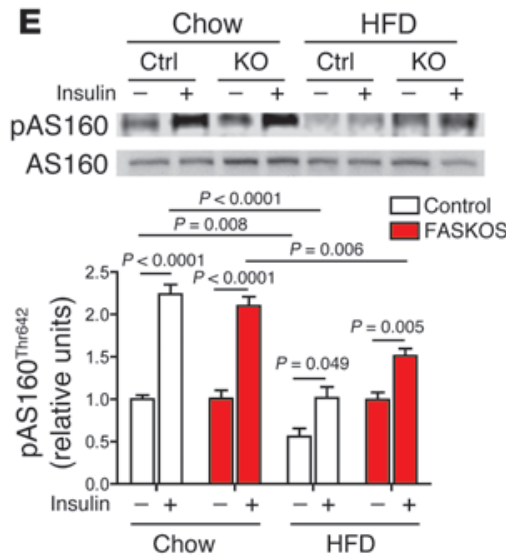

Figure 6

Isolated soleus muscle studies. (A) 2-deoxyglucose (2DG) uptake, (B) pAMPK Trr172, (C) pACCSer79, (D) pAkt Thr308, and (E) pAS160Thr642 ( $n=6$ per group). Data are mean \pm SEM. Representative blots from muscles are also shown.

dependent activation of AMPK to improve glucose metabolism. However, altered calcium handling prevented normal muscle relaxation, leading to disruption of subsequent contraction manifested as decreased overall muscle performance. At the sarcomere, cytosolic calcium binds troponin to release tropomyosin from actin, thus permitting myosin-induced ATP-dependent muscle contraction. During normal relaxation, cytosolic calcium is taken up by the SR, leading to actin-myosin dissociation. Calcium cycling between SR and the cytosol is strictly regulated in striated muscles, and its disruption causes muscle dysfunction (43). Figure 12 depicts the potential relationship among FAS, insulin sensitivity, and weakness in skeletal muscle.

FAS is linked to the generation of phospholipid species that activate nuclear receptors $(17,44)$, consistent with the possibility that FAS is part of a synthetic pathway leading to the production of phospholipids, such as certain PE species, at the SR. However, our data did not establish that FAS enzyme activity is required for effects on SR composition. It is possible that FAS interacts with the SR or SERCA to alter the PC/PE ratio independent of its capacity to convert malonylCoA into palmitate.

Lipids are implicated in the pathogenesis of diet-induced skeletal muscle insulin resistance. This phenomenon is incompletely understood, but a popular explanation is the accumulation of lipid species such as DAG and ceramide that may induce stress kinases, leading to decreased insulin-stimulated Akt phosphorylation (24, 45). Perhaps underappreciated is reduced muscle AMPK activity in insulin resistance $(29,30)$. Skeletal muscles from FASKOS mice were not protected from HFD-induced suppression of insulin-stimulated Akt phosphorylation, but they were protected from a HFD-induced reduction in AMPK activity. DAG, ceramide, and the activities of certain stress kinases were not different in muscles from HFD-fed control and FASKOS mice, which suggests that these mediators are not likely contributors to the insulin sensitivity of FASKOS muscle. Our observations indicate that the insulin-sensitizing phenotype with FAS deficiency is mediated by AMPK, not Akt, and suggest that multiple pathways may be involved in muscle insulin resistance.

FAS affects activity of the nuclear receptor PPAR $\alpha$ in liver (17, 22), brain (46), and macrophages (47), and overexpression of PPAR $\alpha$ in skeletal muscle causes insulin resistance and inactivates AMPK (18), which led us to consider PPAR $\alpha$ as a mediator of the FASKOS phenotype. However, FAS inactivation in muscle did not affect activity of a PPAR $\alpha$ reporter gene, and treatment 
A

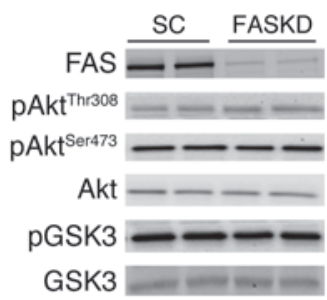

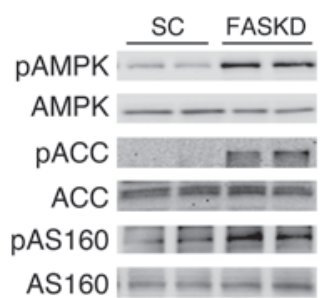

B

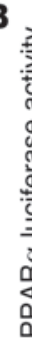

C

\begin{tabular}{|c|c|c|}
\hline & DMSO & WY14643 \\
\hline & SC FASKD & SC $\quad$ FASKD \\
\hline FAS & $=-$ & $-1=$ \\
\hline pAMPK & $-\infty=0$ & $-1=0$ \\
\hline pACC & $a x=-2$ & $=-=$ \\
\hline pAS160 & 1日EE & 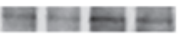 \\
\hline CaMKII & $=-2=$ & $--2=$ \\
\hline pCaMKI & $\Rightarrow=0=$ & 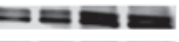 \\
\hline
\end{tabular}

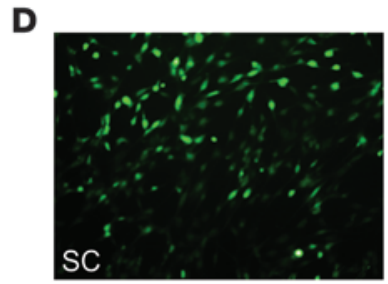

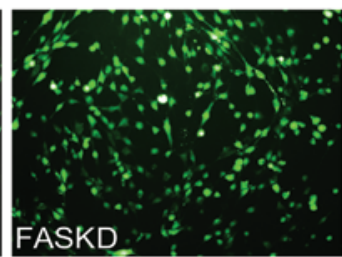

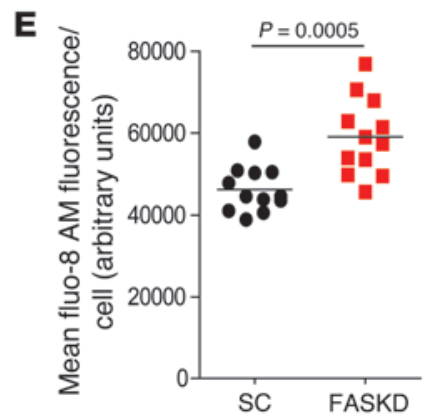

Figure 7

Muscle FAS deletion does not affect PPAR $\alpha$ activity, but increases cytosolic calcium. (A) Western blot analyses of Scrambled (SC) or FASKD C2C12 myocytes. (B) PPAR $\alpha$ luciferase activity in scrambled or FASKD C2C12 myocytes with or without the PPAR $\alpha$ agonist WY14643 $(n=8$ replicate measurements per bar). (C) Western blot analyses of scrambled or FASKD C2C12 myocytes with or without WY14643. (D) Cytosolic calcium in scrambled and FASKD C2C12 myocytes measured using fluo-8 AM. Original magnification, $\times 100$. (E) Quantified fluo-8 AM fluorescence in scrambled and FASKD C2C12 myocytes ( $n=12$ culture wells per condition; horizontal lines denote means). Data are mean \pm SEM.

with a potent PPAR $\alpha$ agonist did not rescue the effect of FAS deletion on AMPK signaling. Similarly, inactivation of FAS in cardiac muscle did not affect PPAR $\alpha$ target genes, but instead activated calcium signaling pathways (33) through incompletely defined mechanisms. The calcium-regulatory mechanism shown here in skeletal muscle may also be involved in the phenotype of mice with FAS knockout in heart (33), another tissue adapted for contractile function, but its relevance to other tissue-specific FAS knockouts is uncertain. Inactivation of pancreatic $\beta$ cell FAS has no effect on insulin secretion, a process requiring dynamic
A

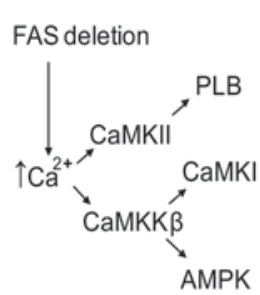

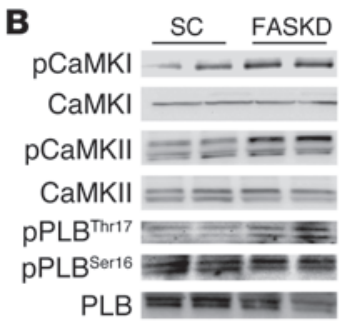

C $\mathrm{pCaMKI}=\underline{=}$
$\mathrm{CaMKI}$
D
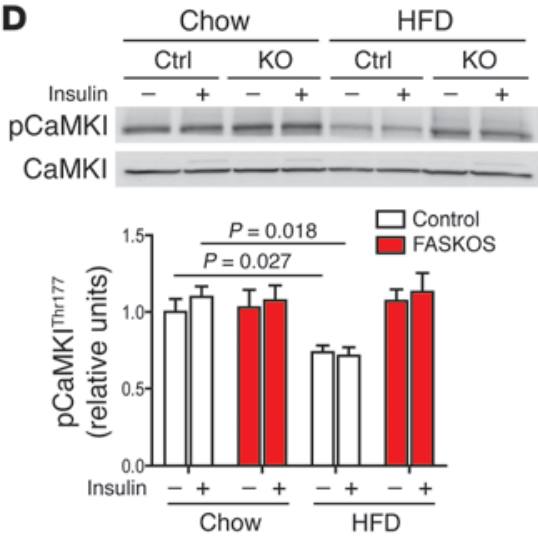

E

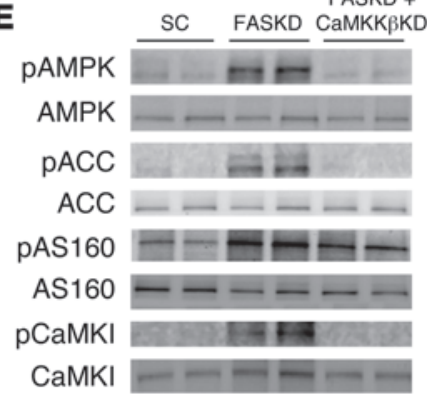

F

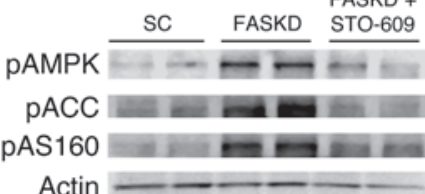

\section{Figure 8}

Muscle FAS deletion induces calcium signaling and activates AMPK through CaMKK $\beta$. (A) Calcium signaling cascade affected by muscle FAS deletion. PLB, phospholamban. (B-D) Western blot analyses for calcium signaling proteins ( $n=6$ per group). Data are mean \pm SEM. Representative blots are also shown. (B) C2C12 myocytes. Phospholamban is phosphorylated by CaMKII on Thr17 and by PKA on Ser16. (C) Muscle from clamp studies of HFD-fed animals. (D) Isolated soleus muscle. (E) Western blot analyses of C2C12 myocytes after FASKD and CaMKK $\beta$ knockdown. (F) Incubation of $\mathrm{C} 2 \mathrm{C} 12$ myocytes with the CaMKK inhibitor STO-609 (10 $\mu \mathrm{g} / \mathrm{ml}$ for 6 hours) eliminated FASKD-induced activation of AMPK signaling. 
A

Histone $\mathrm{H} 3$ (nucleus) COXIV (mitochondria) $\mathrm{Na}^{+} / \mathrm{K}^{+}$-ATPase (PM) GM130 (Golgi)

Calnexin (SR/ER)

p70 (cytoplasm)

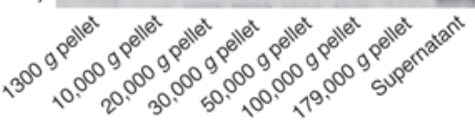

B

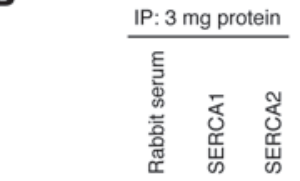

FAS

SERCA1 -

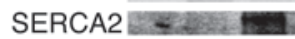

ACC

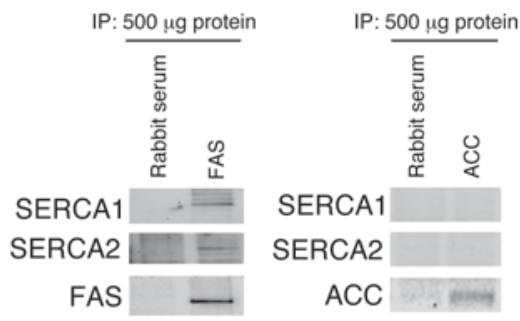

FAS - ACC . A
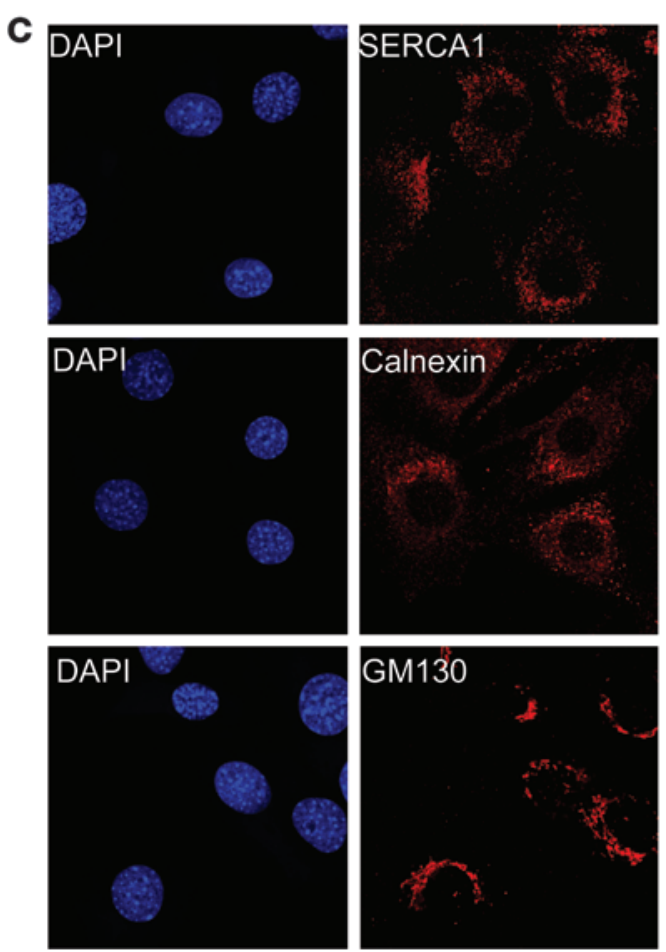

D

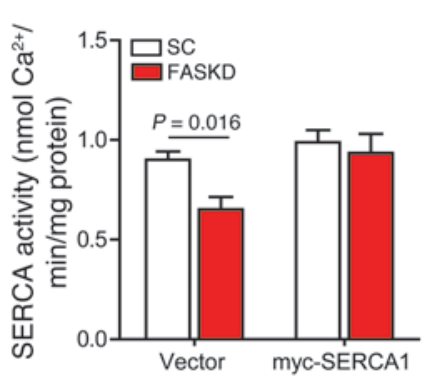

SR: $\begin{aligned} & \text { SERCA1 } \\ & \text { Calnexin } \\ & \end{aligned}$

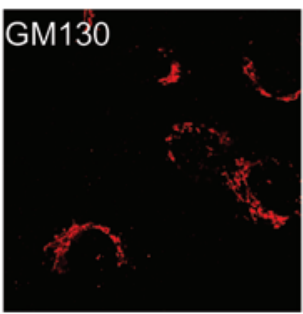

E

AMPK
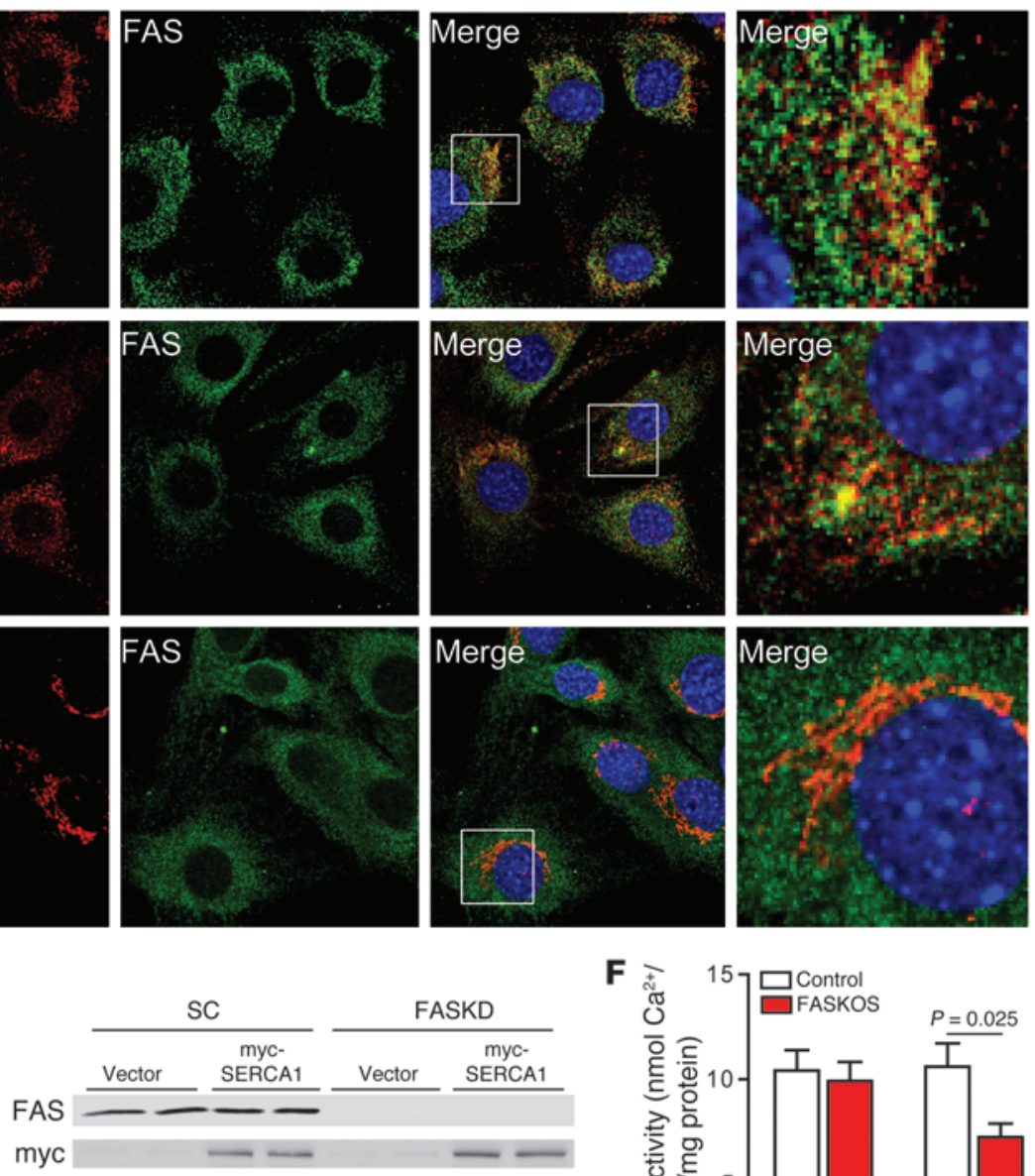

SERCA1 $=-0$

PAMPK $-\div-\div$

$\mathbf{F}$

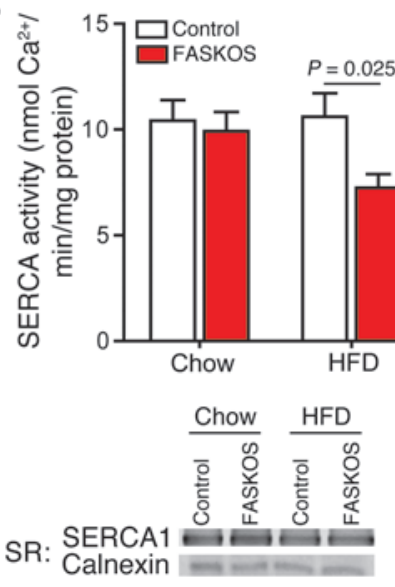

Figure 9

Muscle FAS deletion decreases SERCA activity. (A) Differential centrifugation of mouse hindlimb muscles. PM, plasma membrane; GM130, 130-kDa cis-Golgi matrix protein. (B) Soleus co-IP experiments. FAS, but not ACC, coimmunoprecipitated with SERCA1 or SERCA2 antibody; SERCA1 and SERCA2 coimmunoprecipitated with FAS antibody, but not with ACC antibody. (C) Confocal images of C2C12 cells. Original magnification, $\times 630$. Boxed regions are shown enlarged ( $\times 4$-fold) at far right. (D) Rescue of the FASKD-induced reduction in SERCA enzyme activity by expression of myc-SERCA1 ( $n=8$ replicates per condition). Moreover, SR SERCA abundance with vector treatment was not altered by FASKD (bottom). (E) Expression of myc-SERCA1 reversed FASKD-induced increase in pAMPK. (F) SERCA activity in soleus from chow- or HFD-fed control and FASKOS mice ( $n=6$ per group). SR SERCA abundance is also shown. Data are mean \pm SEM. 
A

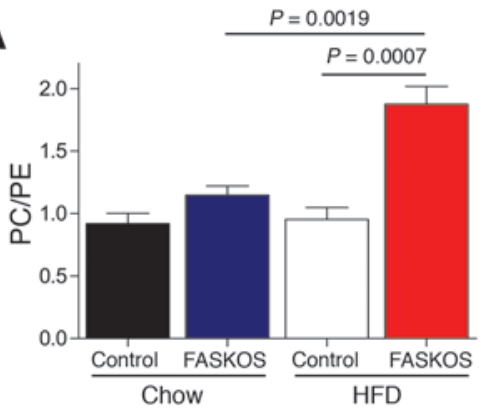

D

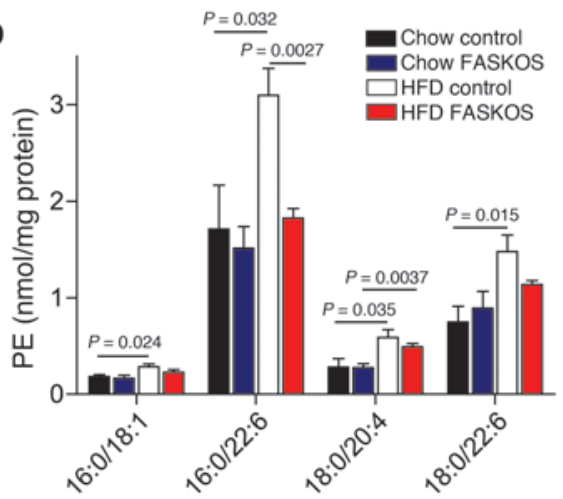

B

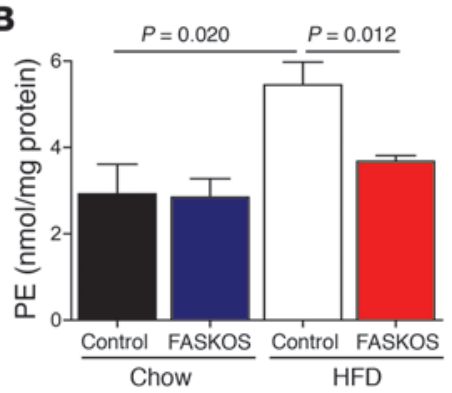

C

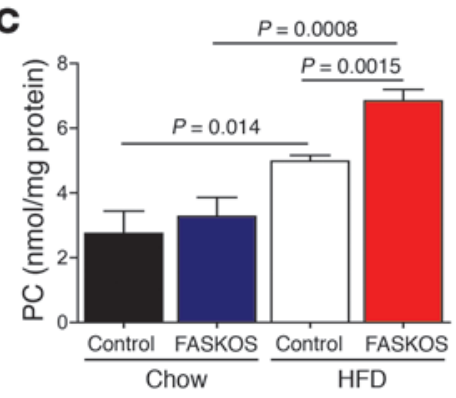

$\mathbf{E}$

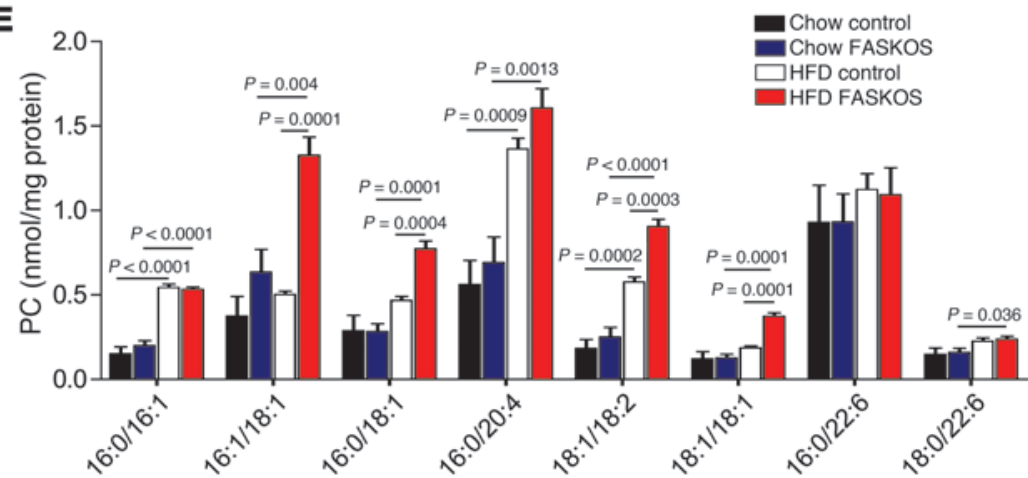

Figure 10

Muscle FAS deletion alters SR phospholipid composition. Mass spectrometry quantification of (A) relative PE and PC abundance, (B and C) total PE and PC, and (D and E) PE and PC species in isolated SR from hindlimb muscles of chow- or HFD-fed control and FASKOS mice $(n=4-6)$. Data are mean \pm SEM.

regulation of intracellular calcium (46), which suggests that in this model, the loss of FAS does not have a major impact on the calcium flux required to release insulin-secretory granules. However, it is possible that the loss of FAS in other nonmuscle tissues alters calcium signaling.

Our data suggest that the induction of FAS by HFD feeding may contribute to skeletal muscle insulin resistance. Although not extensively studied in muscle, FAS regulation involves insulin signaling, the induction of the transcription factor SREBP1c (also known as SREBF1), and other factors (48). In humans, skeletal muscle expression of SREBP1c is highest in individuals that are most insulin resistant (49). This observation is consistent with our present findings in mice, supporting the plausibility of SREBP1cdriven genes such as FAS being increased in muscle in the setting of diet-induced insulin resistance. HFD feeding has been reported to increase SERCA activity in soleus muscle under certain conditions (50), also consistent with our observations linking HFD feeding, FAS, and SERCA.

It is tempting to speculate that HFD-induced FAS expression in muscle represents a selective advantage for mammals. Skeletal muscle's raison d'être is contraction, required for acquiring food, escaping predators, and finding a mate. A HFD-induced increase in muscle FAS may promote insulin resistance, but it may also optimize contractile function. When evolutionary pressures were substantial, mammalian meals were infrequent but high in fat, especially if they consisted of other mammals. Our ancestors probably fasted for prolonged periods while hunting, then feasted for prolonged periods on high-fat prey. Disruption of metabolic homeostasis induced by HFD feeding after fasting may have prompted the selection of animals with the capacity to increase FAS activity in muscle and maintain SERCA activity in order to escape other predators attracted by the same high-fat prey. It has been suggested that insulin resistance is a normal physiological response that limits obesity through mobilization of substrates (51). Our results suggest that, in addition to defending against obesity, insulin resistance maintains muscle strength in the setting of nutrient excess. A HFD-induced increase in skeletal muscle FAS would preserve SERCA activity and normalize force-generating capacity, perhaps selected by evolutionary pressures. It would also increase insulin resistance, probably unrelated to evolutionary pressures since the complications of insulin resistance become manifest well after the next generation is spawned.

Diabetes may have complex effects on skeletal muscle calcium metabolism, since SERCA is decreased in the diabetic soleus muscle (52) and insulin receptor substrate proteins interact with SERCA (53). FAS inhibitors may be useful for treating type 2 diabetes (54). Our findings suggest that these agents might lower blood sugar at the expense of muscle function, identifying a possible side effect of a new class of medication, but also representing a potentially reasonable exchange for modern humans who need to escape the consequences of abnormal glucose metabolism instead of another mammal looking for a meal.

\section{Methods}

Further details are provided in Supplemental Methods.

Animals. Mice with a floxed Fasn locus $\left(\right.$ Fas $\left.^{\text {fl/fl }}\right)$ were crossed with transgenic mice expressing Cre recombinase under the control of the human $\alpha$-skeletal actin (HSA) promoter to obtain FASKOS mice in the C57BL/6J 
A

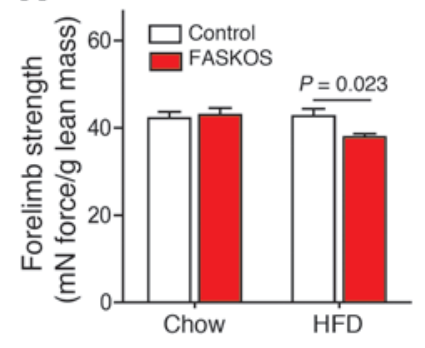

B

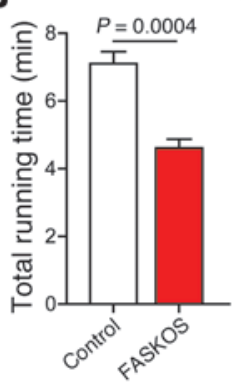

C

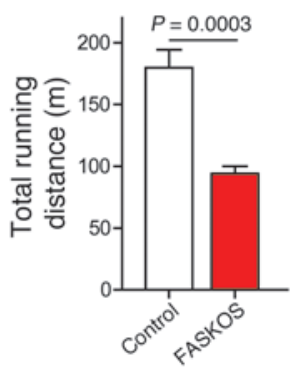

\section{Figure 11}

FASKOS mice are weak. (A) Forelimb strength in chowor HFD-fed control and FASKOS mice ( $n=7$ per group). (B and $\mathbf{C}$ ) Total running time and distance of HFD-fed mice with treadmill sprint interval exercise tests ( $n=6$ per group). Data are mean \pm SEM. background. Fasn and Cre genotyping was performed as described previously (22). Chow diet and HFD were Purina 4043 and Harlan Teklad TD 88137, respectively. Male mice aged 8-12 weeks were used for all experiments. Controls were either Fasn $n^{f / f l}$ mice without the Cre transgene or mice with the Cre transgene alone. The presence of Cre transgene alone did not affect glucose metabolism compared with $\mathrm{Fasn}^{f / f l}$ mice without the transgene (data not shown).

Indirect calorimetry. Indirect calorimetry was performed as described previously (55). $\mathrm{O}_{2}$ consumption $\left(\mathrm{VO}_{2}\right)$ and $\mathrm{CO}_{2}$ production were measured for 24 hours. Mean relative $\mathrm{VO}_{2}$ (expressed in $\mathrm{ml} / \mathrm{kg} / \mathrm{min}$ ) and respiratory quotient (RQ; calculated as $\mathrm{VCO}_{2} / \mathrm{VO}_{2}$ ) were determined for dark and light periods.

$A M P$ and ATP measurements. Frozen muscles were treated with perchloric acid and neutralized with $\mathrm{K}_{2} \mathrm{CO}_{3}$ on ice, and then levels were assayed by HPLC as described previously (56). AMP and ATP were quantified based on peak area compared with a standard curve and normalized to frozen tissue weight.

Fatty acid oxidation determinations. Muscles or cells were processed exactly as described previously (44) in an assay after the conversion of labeled palmitate to labeled $\mathrm{CO}_{2}$ that is trapped in filter paper. Rates of fatty acid oxidation were calculated as nmol ${ }^{14} \mathrm{CO}_{2}$ produced per hour, normalized to tissue weight or cellular protein.

Treadmill sprint interval exercise tests. Mouse treadmill exercise tests used a recently described protocol (57). Fed mice ran intervals of 1 minute each, with a 2 -minute rest between each interval. Running started at a rate of $10 \mathrm{~m} / \mathrm{min}$ and increased by $5 \mathrm{~m} / \mathrm{min}$ at each interval.

Ectopic expression of SERCA1 and SERCA2. The CDNA encoding the mouse enzyme SERCA1 was cloned from PCMV-SPORT6 with mouse SERCA1
CDNA insert (Open Biosystems) by PCR, using the following primers (underline denotes XhoI and XbaI sites): 5'-CTCGAGATGGAGGCCGCGCACTCCAAGTCC- 3 ' and $5^{\prime}$-TCTAGATTATCCCTCCAGATAGTTCCGAGC- ${ }^{\prime}$. The amplified product was subcloned into the pRK5-myc plasmid at its XhoI $\left(5^{\prime}\right)$ and $\mathrm{XbaI}\left(3^{\prime}\right)$ sites to yield an N-terminal myc-tagged construct (pRK5myc-mSERCA1). Transfection-ready pCMV6-XL4-SERCA2 plasmids were purchased from OriGene Technologies. All plasmids were sequenced to confirm their identity and orientation. Differentiated scrambled or FASKD C2C12 myocytes were transfected with pRK5-myc-mSERCA1 or pCMV6XL4-SERCA2 using Lipofectamine 2000 (Invitrogen).

IP. Homogenates were incubated with antibodies (anti-FAS [ab22759], anti-SERCA1 [ab2818], and anti-SERCA2 [ab3625]; Abcam) or normal rabbit serum on a rotator overnight at $4^{\circ} \mathrm{C}$. Protein $\mathrm{A}$ agarose beads were added to the homogenate-antibody mixture for an additional 2 hours at $4^{\circ} \mathrm{C}$. Beads were washed 5 times with PBS, mixed with $2 \times$ Laemmli sample buffer, heated at $95^{\circ} \mathrm{C}$ for 5 minutes, and then subjected to SDS-PAGE for analysis by Western blotting or mass spectrometry.

SERCA activity assay. The calcium transport assay for measuring SERCA activity was adapted from a protocol described previously (58). SR fractions from $\mathrm{C} 2 \mathrm{C} 12$ myocytes or skeletal muscles were isolated by differential centrifugation. The assay mixture contained $100 \mathrm{mM} \mathrm{KCl}, 30 \mathrm{mM}$ imidazolehistidine ( $\mathrm{pH}$ 6.8), $5 \mathrm{mM} \mathrm{MgCl}_{2}, 5 \mathrm{mM} \mathrm{ATP,} 5 \mathrm{mM}(\mathrm{COOK})_{2}, 5 \mathrm{mM} \mathrm{NaN}_{3}$, $1 \mu \mathrm{M}$ Rethenium Red, and $50 \mu \mathrm{M} \mathrm{CaCl}_{2}\left(1 \mu \mathrm{Ci} / \mu \mathrm{mol}\left[{ }^{45} \mathrm{Ca}\right] \mathrm{CaCl}_{2}\right.$; American Radiolabeled Chemicals). The reaction was started by the addition of SR fractions containing $150 \mu \mathrm{g}$ protein for 15 minutes in a $37^{\circ} \mathrm{C}$ water bath, stopped by the addition of $0.15 \mathrm{M} \mathrm{KCl}$ and $1 \mathrm{mM} \mathrm{LaCl}_{3}$, and filtered through a $0.2-\mu \mathrm{m}$ HT Tuffryn membrane (Pall Corp.). SERCA-independent calcium transport was quantified in the presence of $10 \mu \mathrm{M}$ thapsigargin.

\section{Figure 12}

FAS-driven modulation of SERCA activity and cytosolic calcium leads to increased insulin sensitivity and muscle weakness. Increased cytosolic calcium after FAS inactivation likely impairs relaxation of the actin-myosin junction at the sarcomere, promoting muscle weakness. Calcium also likely activates a signaling cascade involving CaMKK $\beta$, AMPK, and AS160 that enhances insulin-stimulated glucose uptake in muscle.

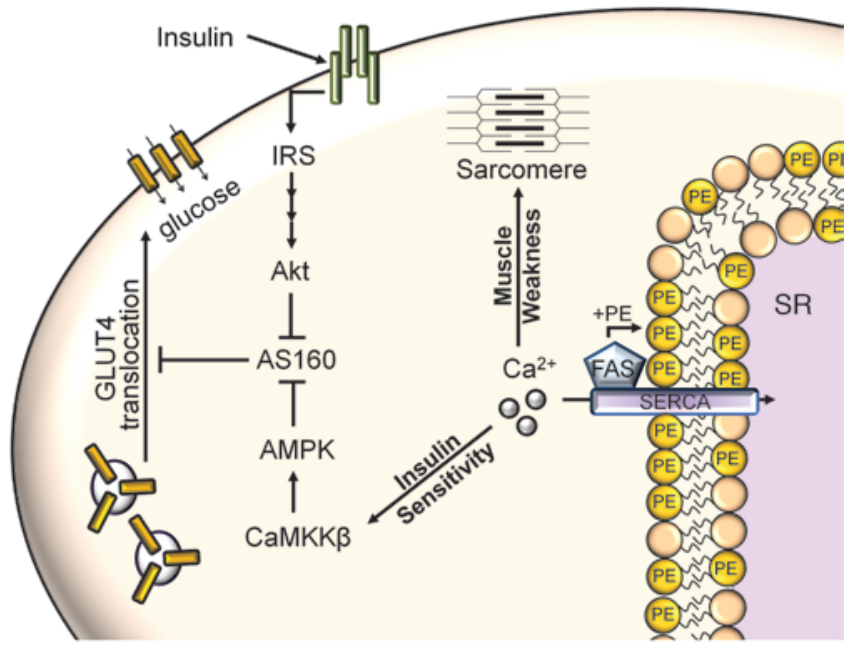


FAS activity assay. FAS enzyme activity was determined using a modification of a previously described assay (59). Freshly harvested muscles were weighed and homogenized in $0.1 \mathrm{M}$ potassium phosphate buffer ( $\mathrm{pH} 7.0$ ) containing $8 \%$ sucrose, $1 \mathrm{mM}$ EDTA ( $\mathrm{pH} 8.0$ ), and $20 \mathrm{mM} 2$-mercaptoethanol at $4^{\circ} \mathrm{C}$. Homogenates were centrifuged at $3,000 \mathrm{~g}$ for 10 minutes at $4^{\circ} \mathrm{C} .10 \mu \mathrm{l}$ of the supernatant was added to $80 \mu \mathrm{l}$ of assay buffer $(0.14 \mathrm{M}$ potassium phosphate buffer [pH 7.0], 1.4 mM EDTA [pH 8.0], $1.4 \mathrm{mM}$ DTT, $0.24 \mathrm{mM} \mathrm{NADPH}$, and $0.1 \mathrm{mM}$ acetyl-CoA), and the rate of NADPH oxidation was monitored at $340 \mathrm{~nm}$. The substrate-dependent rate was determined by subtracting the NADPH oxidation rate from the rate after adding $10 \mu \mathrm{l}$ of $1 \mathrm{mM}$ malonyl-CoA.

Measurement of malonyl-CoA content. Soleus muscles were harvested from mice after a 6-hour fast. Malonyl-CoA was determined in extracts homogenized in deionized water. CoA esters were separated using reverse-phase HPLC on a $5 \mu \mathrm{m}$ Supelco C18 column with a Waters HPLC system, monitoring $254 \mathrm{~nm}$ as the maximal absorbance for CoA. Buffers, gradients, and flow rates were described previously (60).

Statistics. Values are expressed as mean \pm SEM. Statistical comparisons were performed using an unpaired 2-tailed Student's $t$ test (for 2-group analyses) or 2-way ANOVA with Student-Newman-Keuls post-hoc test (for 2-by-2 comparisons). A $P$ value less than 0.05 was considered significant.

Study approval. The Washington University Animal Studies Committee approved all protocols.

\section{Acknowledgments}

This work was supported by NIH grants DK076729, DK088083, T32 DK007120, DK20579, and DK56341 and by fellowship grants from the American Diabetes Association and the American Heart Association.

Received for publication July 10, 2012, and accepted in revised form December 14, 2012.

Address correspondence to: Clay F. Semenkovich, Division of Endocrinology, Metabolism and Lipid Research, Department of Medicine, Washington University School of Medicine, 660 South Euclid Avenue, Box 8127, St. Louis, Missouri 63110, USA. Phone: 314.362.7617; Fax: 314.362.7641; E-mail: csemenko@wustl.edu.
1. Seshasai SR, et al. Diabetes mellitus, fasting glucose, and risk of cause-specific death. N Engl J Med. 2011;364(9):829-841.

2. Saltiel AR. New perspectives into the molecular pathogenesis and treatment of type 2 diabetes. Cell. 2001;104(4):517-529.

3. Schenk S, Saberi M, Olefsky JM. Insulin sensitivity: modulation by nutrients and inflammation. J Clin Invest. 2008;118(9):2992-3002.

4. DeFronzo RA, Gunnarsson R, Bjorkman O, Olsson $\mathrm{M}$, Wahren J. Effects of insulin on peripheral and splanchnic glucose metabolism in noninsulindependent (type II) diabetes mellitus. J Clin Invest. 1985;76(1):149-155.

5. McGarry JD. What if Minkowski had been ageusic? An alternative angle on diabetes. Science. 1992; 258(5083):766-770.

6. Ferreira LD, Pulawa LK, Jensen DR, Eckel RH. Overexpressing human lipoprotein lipase in mouse skeletal muscle is associated with insulin resistance. Diabetes. 2001;50(5):1064-1068.

7. Liu L, Zhang Y, Chen N, Shi X, Tsang B, Yu YH. Upregulation of myocellular DGAT1 augments triglyceride synthesis in skeletal muscle and protects against fat-induced insulin resistance. J Clin Invest. 2007;117(6):1679-1689.

8. Haemmerle G, et al. Defective lipolysis and altered energy metabolism in mice lacking adipose triglyceride lipase. Science. 2006;312(5774):734-737.

9. Choi CS, et al. Continuous fat oxidation in acetylCoA carboxylase 2 knockout mice increases total energy expenditure, reduces fat mass, and improves insulin sensitivity. Proc Natl Acad Sci U S A. 2007; 104(42):16480-16485.

10. Koonen DP, et al. Alterations in skeletal muscle fatty acid handling predisposes middle-aged mice to diet-induced insulin resistance. Diabetes. 2010; 59(6):1366-1375.

11. Wang H, et al. Skeletal muscle-specific deletion of lipoprotein lipase enhances insulin signaling in skeletal muscle but causes insulin resistance in liver and other tissues. Diabetes. 2009;58(1):116-124.

12. Funai K, Semenkovich CF. Skeletal muscle lipid flux: running water carries no poison. Am J Physiol Endocrinol Metab. 2011;301(2):E245-E251.

13. Muoio DM, Neufer PD. Lipid-induced mitochondrial stress and insulin action in muscle. Cell Metab. 2012;15(5):595-605.

14. Maier T, Leibundgut M, Ban N. The crystal structure of a mammalian fatty acid synthase. Science. 2008;321(5894):1315-1322.

15. Pender C, Trentadue AR, Pories WJ, Dohm GL,
Houmard JA, Youngren JF. Expression of genes regulating malonyl-CoA in human skeletal muscle. J Cell Biochem. 2006;99(3):860-867.

16. Lodhi IJ, Wei X, Semenkovich CF. Lipoexpediency: de novo lipogenesis as a metabolic signal transmitter. Trends Endocrinol Metab. 2011;22(1):1-8.

17. Chakravarthy MV, et al. Identification of a physiologically relevant endogenous ligand for PPARalpha in liver. Cell. 2009;138(3):476-488.

18. Finck BN, et al. A potential link between muscle peroxisome proliferator- activated receptor-alpha signaling and obesity-related diabetes. Cell Metab. 2005;1(2):133-144.

19. Kersten S. Mechanisms of nutritional and hormonal regulation of lipogenesis. EMBO Rep. 2001; 2(4):282-286

20. Coupe C, Perdereau D, Ferre P, Hitier Y, Narkewicz $M$, Girard J. Lipogenic enzyme activities and mRNA in rat adipose tissue at weaning. Am J Physiol. 1990;258(1 pt 1):E126-E133.

21. Kraegen EW, James DE, Storlien LH, Burleigh KM, Chisholm DJ. In vivo insulin resistance in individual peripheral tissues of the high fat fed rat: assessment by euglycaemic clamp plus deoxyglucose administration. Diabetologia. 1986;29(3):192-198.

22. Chakravarthy MV, et al. "New" hepatic fat activates PPARalpha to maintain glucose, lipid, and cholesterol homeostasis. Cell Metab. 2005;1(5):309-322.

23. Miniou P, Tiziano D, Frugier T, Roblot N, Le Meur $\mathrm{M}$, Melki J. Gene targeting restricted to mouse striated muscle lineage. Nucleic Acids Res. 1999;27(19):e27.

24. Samuel VT, Shulman GI. Mechanisms for insulin resistance: common threads and missing links. Cell. 2012;148(5):852-871.

25. Kane S, et al. A method to identify serine kinase substrates. Akt phosphorylates a novel adipocyte protein with a Rab GTPase-activating protein (GAP) domain. J Biol Chem. 2002;277(25):22115-22118.

26. Cartee GD, Funai K. Exercise and insulin: Convergence or divergence at AS160 and TBC1D1? Exerc Sport Sci Rev. 2009;37(4):188-195.

27. Funai K, Cartee GD. Inhibition of contraction-stimulated AMP-activated protein kinase inhibits contraction-stimulated increases in PAS-TBC1D1 and glucose transport without altering PAS-AS160 in rat skeletal muscle. Diabetes. 2009;58(5):1096-1104.

28. Chen S, Murphy J, Toth R, Campbell DG, Morrice NA, Mackintosh C. Complementary regulation of TBC1D 1 and AS160 by growth factors, insulin and AMPK activators. Biochem J. 2008;409(2):449-459.

29. Steinberg GR, et al. Tumor necrosis factor alphainduced skeletal muscle insulin resistance involves suppression of AMP-kinase signaling. Cell Metab. 2006;4(6):465-474.

30. Fujii N, et al. Ablation of AMP-activated protein kinase alpha2 activity exacerbates insulin resistance induced by high-fat feeding of mice. Diabetes. 2008;57(11):2958-2966

31. Seale P, et al. PRDM16 controls a brown fat/skeletal muscle switch. Nature. 2008;454(7207):961-967.

32. Hardie DG. AMP-activated protein kinase: an energy sensor that regulates all aspects of cell function. Genes Dev. 2011;25(18):1895-1908.

33. Razani B, et al. Fatty acid synthase modulates homeostatic responses to myocardial stress. J Biol Chem. 2011;286(35):30949-30961.

34. Xie X, et al. C2 domain-containing phosphoprotein CDP138 regulates GLUT4 insertion into the plasma membrane. Cell Metab. 2011;14(3):378-389.

35. Kramer HF, Taylor EB, Witczak CA, Fujii N, Hirshman MF, Goodyear LJ. Calmodulin-binding domain of AS160 regulates contraction- but not insulinstimulated glucose uptake in skeletal muscle. Diabetes. 2007;56(12):2854-2862.

36. Wright DC, Hucker KA, Holloszy JO, Han DH. $\mathrm{Ca} 2+$ and AMPK both mediate stimulation of glucose transport by muscle contractions. Diabetes. 2004;53(2):330-335.

37. Wei $\mathrm{X}$, et al. De novo lipogenesis maintains vascular homeostasis through endothelial nitric-oxide synthase (eNOS) palmitoylation. J Biol Chem. 2011;286(4):2933-2945.

38 . Wei X, et al. Fatty acid synthase modulates intestinal barrier function through palmitoylation of mucin 2. Cell Host Microbe. 2012;11(2):140-152.

39. Gustavsson M, Traaseth NJ, Veglia G. Activating and deactivating roles of lipid bilayers on the $\mathrm{Ca}(2+)$-ATPase/phospholamban complex. Biochemistry. 2011;50(47):10367-10374.

40. Fu S, et al. Aberrant lipid metabolism disrupts calcium homeostasis causing liver endoplasmic reticulum stress in obesity. Nature. 2011;473(7348):528-531.

41. Pan Y, et al. Targeted disruption of the ATP2A1 gene encoding the sarco(endo)plasmic reticulum Ca2+ ATPase isoform 1 (SERCA1) impairs diaphragm function and is lethal in neonatal mice. J Biol Chem. 2003;278(15):13367-13375.

42. Goonasekera SA, et al. Mitigation of muscular dystrophy in mice by SERCA overexpression in skeletal muscle. J Clin Invest. 2011;121(3):1044-1052.

43. Maclennan DH, Zvaritch E. Mechanistic models for muscle diseases and disorders originating in the sarcoplasmic reticulum. Biochim Biophys Acta. 2011;1813(5):948-964. 
44. Lodhi IJ, et al. Inhibiting adipose tissue lipogenesis reprograms thermogenesis and PPARgamma activation to decrease diet-induced obesity. Cell Metab. 2012;16(2):189-201.

45. Chavez JA, Summers SA. A ceramide-centric view of insulin resistance. Cell Metab. 2012;15(5):585-594.

46. Chakravarthy MV, et al. Brain fatty acid synthase activates PPARalpha to maintain energy homeostasis. J Clin Invest. 2007;117(9):2539-2552.

47. Schneider JG, et al. Macrophage fatty-acid synthase deficiency decreases diet-induced atherosclerosis. J Biol Chem. 2010;285(30):23398-23409.

48. Jensen-Urstad AP, Semenkovich CF. Fatty acid synthase and liver triglyceride metabolism: Housekeeper or messenger? Biochim Biophys Acta. 2012. 1821(5):747-753.

49. Jans A, et al. Transcriptional metabolic inflexibility in skeletal muscle among individuals with increasing insulin resistance. Obesity. 2011;19(11):2158-2166.

50. Aagaard L, Nawrocki A, Madsen K. Effect of high- fat diet on sarcoplasmic reticulum $\mathrm{Ca}(++)$-ATPase activity in different types of rat skeletal muscle. Rocz Akad Med Bialymst. 2002;47:31-39.

51. Saltiel AR. Insulin resistance in the defense against obesity. Cell Metab. 2012;15(6):798-804.

52. Racz G, Szabo A, Ver A, Zador E. The slow sarco/ endoplasmic reticulum $\mathrm{Ca} 2+$-ATPase declines independently of slow myosin in soleus muscle of diabetic rats. Acta Biochim Polonica. 2009;56(3):487-493.

53. Algenstaedt P, Antonetti DA, Yaffe MB, Kahn CR. Insulin receptor substrate proteins create a link between the tyrosine phosphorylation cascade and the Ca2+-ATPases in muscle and heart. J Biol Chem. 1997;272(38):23696-23702.

54. Wu M, et al. Antidiabetic and antisteatotic effects of the selective fatty acid synthase (FAS) inhibitor platensimycin in mouse models of diabetes. Proc Natl Acad Sci U S A. 2011;108(13):5378-5383.

55. Bernal-Mizrachi C, et al. Respiratory uncoupling lowers blood pressure through a leptin-dependent mechanism in genetically obese mice. Arterioscler Thromb Vasc Biol. 2002;22(6):961-968.

56. Yoshino J, Mills KF, Yoon MJ, Imai S. Nicotinamide mononucleotide, a key $\mathrm{NAD}(+)$ intermediate, treats the pathophysiology of diet- and age-induced diabetes in mice. Cell Metab. 2011;14(4):528-536.

57. Gan Z, et al. The nuclear receptor PPARbeta/delta programs muscle glucose metabolism in cooperation with AMPK and MEF2. Genes Dev. 2011; 25(24):2619-2630.

58. Moore L, Chen T, Knapp HRJr, Landon EJ. Energydependent calcium sequestration activity in rat liver microsomes. J Biol Chem. 1975;250(12):4562-4568.

59. Ullman AH, White HB 3rd. Assay of fatty acid synthase using a bicyclic dione as substrate. Methods Enzymol. 1981;72:303-306.

60. Pizer ES, et al. Malonyl-coenzyme-A is a potential mediator of cytotoxicity induced by fatty-acid synthase inhibition in human breast cancer cells and xenografts. Cancer Res. 2000;60(2):213-218. 